\title{
The clinical validation of a specific (HDSS) scale: a measurement of harmonic/disharmonic within the geometry of the spine in the
} saggittal plane

\author{
Manuel Rigo, Monica Villagrasa* and Gloria Quera-Salvá
}

Address: E. Salvá Institute, Barcelona, Spain

* Corresponding author

from $5^{\text {th }}$ International Conference on Conservative Management of Spinal Deformities

Athens, Greece. 3-5 April 2008

Published: 15 January 2009

Scoliosis 2009, 4(Suppl I):O52 doi:10.1 186/1748-716I-4-SI-O52

This abstract is available from: http://www.scoliosisjournal.com/content/4/SI/O52

(C) 2009 Rigo et al; licensee BioMed Central Ltd.

\section{Background}

Using the Formetric ${ }^{\circledR}$ system, we have observed a high incidence of abnormal sagittal configurations in scoliotic as well as in non scoliotic patients. Those abnormal configurations could be described by using terms like Hyper- or Hypo- but not all of them. Changes in the location of the thoracic apex, lordotic apex, transitional point as well as segmental rectifications of the profile were observed with the formetric. This data is used to define a specific scale to measure harmony of the spine.

\section{Materials and methods}

This scale, a simplified version of the 2007 original presented at the SOSORT meeting, uses four items: kyphosis apex, lordotic apex, transitional point and number of rectified segments. The HDSS ranges from 0 (harmonic) to 16 (disharmonic). The scale has been clinically validated in 157 scoliotic patients. These groups are divided into four groups according to their visual harmonic or disharmonic profile as determined by an expert clinician.

\section{Results}

The HDSS took a significant different value in the four groups. First the groups are divided in two main groups: those with more harmonic profiles $(\mathrm{N}=77$, HDSS $=2.9 \pm$ $1.1)$ and those with more disharmonic profiles $(\mathrm{N}=80$, HDSS $=8.2 \pm 2.4)$. The differences of the two main groups are highly significant $(\mathrm{p}>.001)$. The system and the scale were reliable.

\section{Conclusion}

The HDSS is a useful tool to measure how harmonic/disharmonic the geometry of the spine is in the sagittal plane.

\section{References}

I. Duval Beaupere G, Taussing G, Mouilleseaux B, Pries P, Mounier C: Pronostic Factors for Idiopathic Scoliosis. In Dr Jean Dansereau Scientific editor: International Symposium on 3D Scoliotic Deformities joined with the VIlth International Symposium on Spinal Deformity and Surface Topography. Éditions de l'École Polytechnique de Montréal Gustav Fisher Verlag; 1992:2III-2I6.

2. Singer KP, Goh S, Leedman P, Price RI: Reliability of Rasterstereography of Thoracic Kyphosis. Stud in Health Technol Inform I999, 59:29-32. 